\title{
Interlocuções com Marilyn Cochran-Smith sobre aprendizagem e pesquisa do professor em comunidades investigativas*
}

\author{
DARIO FIORENTINI \\ Universidade Estadual de Campinas, Campinas, SP, Brasil \\ VANESSA CRECCI \\ Universidade Estadual de Campinas, Campinas, SP, Brasil
}

RESUMO

Este artigo apresenta e discute a vida e a obra de Marilyn Cochran-Smith, bem como seus principais constructos teóricos, desenvolvidos com a colaboração de Susan Lytle, tais como: comunidades investigativas, investigação do professor, postura investigativa e formação de professores para a justiça social. Também são mencionados estudos e autores brasileiros que estabelecem interlocução com as ideias dessas autoras. Algumas contribuições e influências de Cochran-Smith e Lytle são destacadas em relação a esses estudos, principalmente aquelas relacionadas à pesquisa do professor sobre sua prática e à pesquisa sobre aprendizagem e desenvolvimento do professor em comunidades investigativas. Por fim, para ampliar o debate acerca dessas ideias e obter sua opinião atual sobre o movimento da pesquisa do professor e a política de educação do Governo Obama, é apresentada entrevista completa realizada pelos autores com Cochran-Smith, em 2012, no Boston College.

\section{PALAVRAS-CHAVE}

formação docente; comunidades investigativas; Marilyn Cochran-Smith; aprendizagem docente; postura investigativa.

* Este trabalho contou com apoio financeiro da Fundação de Amparo à Pesquisa do Estado de São Paulo (FAPESP) (Processo BEPE 2012/13827-8) e faz parte de um projeto maior do autor Dario Fiorentini, financiado pelo Conselho Nacional de Desenvolvimento Científico e Tecnológico (CNPq) (PQ1D). 


\section{DIALOGUES WITH MARILYN COCHRAN-SMITH ON LEARNING AND TEACHER RESEARCH IN COMMUNITIES OF INQUIRY}

\section{ABSTRACT}

This paper presents and discusses the life and intellectual production of Marilyn Cochran-Smith, as well as the major theoretical constructs developed by her in collaboration with Susan Lytle, such as communities of inquiry, teacher research, inquiry as stance and teacher learning for social justice. It also lists some Brazilian authors and studies that have attempted to use Cochran-Smith's concepts and to establish dialogues based on the ideas developed by her and Lytle. Some contributions made by the authors to these studies are emphasized, particularly in relation to teacher research and to the learning and development in teacher inquiry communities. Finally, to increase the debate about these ideas, and get her current opinion about the teacher's research and the Obama administration's education policies, the full text of the interview conducted by the authors with Cochran-Smith is presented. The interview took place in December 2012, at Boston College.

\section{KEYWORDS}

teacher education; inquiry communities; Marilyn Cochran-Smith; teacher learning; inquiry as stance.

\section{DIÁLOGOS CON MARILYN COCHRAN-SMITH SOBRE APRENDIZAJE E INVESTIGACIÓN DOCENTE EN LAS COMUNIDADES DE INVESTIGACIÓN}

\section{RESUMEN}

Este artículo presenta y discute la vida y obra de Marilyn Cochran-Smith, así como sus principales constructos teóricos, desarrollados en colaboración con Susan Lytle, tales como: comunidades investigativas, investigación del profesor, postura investigativa y formación de profesores para la justicia social. También menciona estudios y autores brasileños que establecen diálogos con las ideas de esas autoras. Destacan algunas influencias y contribuciones de Cochran-Smith y Lytle relativas a estos estudios, sobre todo aquellas relacionadas con la investigación del profesor sobre su práctica, y a la investigación sobre el aprendizaje y el desarrollo del profesor en comunidades investigativas. Por último, para ampliar el debate sobre tales ideas y obtener su visión actual del movimiento de investigación del profesor y la política educativa del gobierno Obama, se presenta una entrevista completa realizada el 2012 por los autores a Cochran-Smith, en el Boston College.

\section{PALABRAS CLAVE}

formación docente; comunidades investigativas; Marilyn Cochran-Smith; aprendizaje docente; postura investigativa. 


\section{INTRODUÇÃO}

À medida que nos dedicamos a compreender conceitos como aprendizagem docente, pesquisa do professor, comunidades investigativas, desenvolvimento profissional, entre outros aspectos relacionados à formação docente, surge a necessidade de analisar e discutir os sentidos e os pressupostos que perpassam cada uma dessas ideias. Tais análises são necessárias, sobretudo, no atual contexto em que esses conceitos, inicialmente concebidos em cenários críticos, são projetados, propostos, implementados ou transpostos na prática com diferentes interpretações, apropriações e intencionalidades. Se, por um lado, essas ideias ainda encontram espaço em estudos e práticas de pesquisadores, formadores e professores que criticam e tentam romper com o modelo da racionalidade técnica, por outro também as encontramos em proposições de governos e de acadêmicos habituados a colonizar as práticas docentes.

Para compreender e discutir esse cenário, temos encontrado respaldo nos estudos de Marylin Cochran-Smith e Susan Lytle, que há mais de três décadas rejeitam o pressuposto de que o conhecimento da prática pedagógica é gerado de "fora para dentro", isto é, por pesquisadores universitários distanciados das práticas escolares (Cochran-Smith; Lytle, 1993).

$\mathrm{E}$ foi em razão das contribuições dessas autoras que tivemos a oportunidade de entrevistar a professora doutora Marilyn Cochran-Smith, em sua sala, no prédio do Lynch School of Education, no Boston College.

Neste artigo-entrevista, inicialmente apresentamos alguns aspectos da história da autora, as principais obras e construtos teóricos desenvolvidos por ela em colaboração com sua principal parceira intelectual: Susan Lytle. A seguir, mencionamos alguns autores e estudos brasileiros que têm tentado utilizar os conceitos de Cochran-Smith e Lytle e estabelecer interlocução com suas ideias. Nesse contexto, destacamos, topicamente, algumas influências e contribuições dos estudos dessas autoras, principalmente em relação à prática e à pesquisa brasileira sobre formação de professores. Por último, trazemos aos educadores brasileiros a íntegra da entrevista que realizamos com ela, em dezembro de $2012 .{ }^{1} \mathrm{Na}$ entrevista, procuramos destacar a trajetória de estudo da pesquisadora Marylin Cochran-Smith e de sua parceria com Susan Lytle acerca do movimento da pesquisa do professor e o processo de investigação da prática docente, com destaque para a aprendizagem e o desenvolvimento do professor em comunidades investigativas. Além disso, tentamos conhecer a opinião da pesquisadora em relação à atual política do Governo Obama sobre a educação e, especialmente, sobre a pesquisa e a formação de professores nos Estados Unidos.

1 Cabe destacar que a entrevista foi transcrita em inglês, traduzida para o português, revisada pelos autores, traduzida novamente para o inglês, tendo sido essa última versão revisada e validada por Cochran-Smith em junho de 2014. 


\section{SOBRE A PROFESSORA MARYLIN COCHRAN-SMITH}

Como muitas mulheres da classe trabalhadora que chegaram ao ensino superior nos Estados Unidos, Marylin Cochran-Smith, logo após a conclusão do curso de educação elementar, sendo especialista em leitura e linguagem, começou a lecionar na escola elementar, ao final da década de 1960. Influenciada pela perspectiva sociocultural de ensino e aprendizagem, por perspectivas críticas e pelas abordagens emergentes de pesquisa qualitativa e etnográfica, iniciou seus estudos em nível de pós-graduação, tendo concluído doutorado em educação, com ênfase em linguagem, ensino e literatura.

Há mais de trinta anos têm direcionado suas pesquisas e publicações à formação de professores, tendo como principais tópicos de estudo: comunidades investigativas, pesquisa do professor, formação docente para a justiça social. A professora e pesquisadora conta, atualmente, com cerca de cento e cinquenta artigos e capítulos de livros publicados e nove livros escritos com o tom e o vigor de quem acredita e vivencia as ideias que propõe e defende. Quatro desses livros ganharam prêmios nacionais, entre os quais destacamos o último, escrito em 2009 em coautoria com Susan Lytle, intitulado Inquiry as stance: practitioner research for the next generation.

Suas publicações mais recentes têm como foco a pesquisa sobre formação de professores e as políticas públicas relativas à qualidade de ensino e às agendas das reformas educacionais. E impossível falar de sua obra sem citar sua parceria intelectual com Susan Lytle. ${ }^{2}$ Juntas escreveram diversos artigos e dois importantes livros (Cochran-Smith; Lytle, 1993, 2009) que teorizam sobre a pesquisa e a aprendizagem docente na intersecção entre a pesquisa e a prática de formação de professores (Cochran-Smith, 2012). Na verdade, foi com base na experiência com o desenvolvimento de programas de formação inicial e continuada de professores que notaram grandes lacunas entre o discurso da universidade e a realidade cotidiana das escolas. Ao vivenciarem dilemas entre esses dois mundos, passaram a rejeitar a ideia de que os especialistas - externos à comunidade escolar - devem ser os agentes primários das reformas escolares. Perceberam, assim, que os acadêmicos não eram os únicos críticos acerca dos arranjos políticos e sociais da escola.

Ressalta-se, além disso, sua atuação e liderança na comunidade científica norte-americana, tendo sido presidente da American Educational Research Association (AERA) nos anos de 2004 e 2005. Atualmente é membro eleito da Academia Nacional de Educação dos Estados Unidos e dirige o programa de doutorado em currículo e instrução da Lynch School of Education, no Boston College.

2 Susan Lytle começou sua carreira como professora de inglês em escolas secundárias. Na Universidade da Pensilvânia, desde os anos de 1970, tem supervisionado estagiários. Atualmente é diretora do Programa de Pós-Graduação em Letramento, Leitura e Escrita. É também diretora de um projeto colaborativo entre acadêmicos e professores do distrito da Filadélfia, que tem sido o principal local de pesquisa sobre investigação do professor. 


\section{PESQUISA DO PROFESSOR, COMUNIDADES INVESTIGATIVAS E INVESTIGAÇÃO COMO POSTURA}

Em 1990, tomando por base os estudos de Lee S. Shulman, Cochran-Smith e Lytle apontaram que as pesquisas em educação poderiam ser categorizadas em dois paradigmas: 1) o processo-produto, envolvendo pesquisas que correlacionavam o comportamento dos professores com o desempenho dos estudantes; e 2) o qualitativo ou interpretativo, contemplando pesquisas provenientes (ou fortemente vinculados aos campos) da sociologia, da antropologia e da linguística, e que se propunham a descrever detalhadamente as práticas do ensino e de seus contextos. Para elas, ambos os paradigmas tornavam os professores invisíveis enquanto criadores de conhecimentos sobre o ensino e a aprendizagem na prática escolar.

Foi, então, sob a influência dos estudos de Henry A. Giroux, Dixie Goswani, Lawrence Stenhouse e John Elliot, que Cochran-Smith e Lytle compreenderam que faltava a base de conhecimentos sobre educação, que faltavam vozes, perguntas, narrativas, pesquisas e compreensões sobre a prática profissional produzidos e sistematizados pelos próprios professores. Situação essa que limitava as prerrogativas do ensino aos critérios e julgamentos tão somente da comunidade acadêmica. Para transformar esse cenário, passaram a discutir a diferença entre a pesquisa do professor e a pesquisa acadêmica, destacando que não se tratava de hierarquizá-las, mas de reconhecer as peculiaridades e importância de cada uma delas (Cochran-Smith; Lytle, 1990).

Em 1993, lançaram o primeiro livro em parceria intitulado Inside/outside: teacher research and knowledge, no qual deram continuidade ao questionamento sobre a direção de mão única do contexto no qual o conhecimento pedagógico é gerado na universidade para ser aplicado nas escolas, em um movimento de "fora para dentro". Em uma tentativa de romper com esse status quo do campo de estudos e práticas sobre formação docente, passaram a defender que a pesquisa do professor poderia alterar a base dos conhecimentos em educação. Para isso, a pesquisa deveria ser intencional, sistemática e realizada por professores, podendo ser caracterizada em, pelo menos, duas categorias e quatro modalidades (Quadro 1).

Cabe destacar que a intenção das autoras com essa tipologia da pesquisa docente não foi a de torná-la exclusiva ou propor modelos de pesquisa do professor. Visava, principalmente, identificar e reconhecer diferentes modos de produção de conhecimento e de escrita do professor, colocando em evidência a vasta gama de questões de estudo e investigação, os diferentes modos de análise e interpretação das práticas escolares e suas implicações no trabalho de sala de aula (Cochran-Smith; Lytle, 1993).

Após uma década de estudos e investigações, esse movimento de pesquisa do professor ganhou fôlego nos Estados Unidos, tanto que as autoras publicaram o artigo "The teacher research movement: a decade later" (Cochran-Smith; Lytle, 1999b). Nesse artigo, apontam que já era possível dizer que o interesse da/na pesquisa do professor não fora apenas um modismo. Destacam também que o tema despertava aspirações que partiam de diferentes compromissos políticos e ideológicos, bem 
como contemplava diferentes concepções de aprendizagem de professores e futuros professores.

Quadro 1 - Pesquisa do professor: um quadro analítico

\begin{tabular}{|c|c|}
\hline \multicolumn{2}{|c|}{$\begin{array}{l}\text { Pesquisa do professor } \\
\text { Investigação sistemática e intencional sobre o ensino, a aprendizagem e a } \\
\text { escolarização realizada por professores em suas escolas e salas de aula }\end{array}$} \\
\hline $\begin{array}{c}\text { Pesquisa empírica } \\
\text { (análise e interpretação de dados) }\end{array}$ & $\begin{array}{l}\text { Pesquisa conceitual } \\
\text { (teórica/filosófica, trabalho } \\
\text { com análise de ideias) }\end{array}$ \\
\hline $\begin{array}{l}\text { Tipo } 1 \text { - Diários: descrições dos professores sobre suas aulas. } \\
\text { • Observações registradas. } \\
\text { • Análise de experiências. } \\
\text { • Reflexões e interpretações sobre práticas. } \\
\text { Tipo } 2 \text { - Investigações orais: reflexões orais sobre questões, } \\
\text { contextos e experiências da sala de aula/escola. } \\
\text { • Análises e intepretações colaborativas. } \\
\text { • Exploração das relações entre casos de sala de aula e teorias } \\
\text { do campo da educação. } \\
\text { Tipo } 3 \text { - Estudos da sala de aula: exploração docente sobre } \\
\text { questões práticas utilizando dados de observação, entrevistas e } \\
\text { análise de documentos. } \\
\text { • Formulação de perguntas. } \\
\text { • Trabalho individual e colaborativo. }\end{array}$ & $\begin{array}{l}\text { Tipo 4- Ensaio: interpretações dos } \\
\text { professores dos pressupostos e das } \\
\text { características do cotidiano escolar } \\
\text { e/ou da própria pesquisa. } \\
\text { - Reflexões sobre os trabalhos dos } \\
\text { alunos e professores, bem como } \\
\text { de textos publicados (currículo, } \\
\text { investigação empírica ou } \\
\text { conceitual e bibliografia sobre o } \\
\text { campo). } \\
\text { - Seleção de exemplos particulares } \\
\text { que apoiam informações gerais. }\end{array}$ \\
\hline
\end{tabular}

Fonte: Cochran-Smith e Lylte (1993, p. 27, tradução nossa).

Nesse artigo, ainda, rebatem as críticas que desqualificavam a pesquisa do professor em detrimento da acadêmica. Assim, indicam que, apesar da lentidão das mudanças nas universidades, já era possível observar evidências de que a pesquisa do professor sobre sua prática teria tido efeito transformador na cultura acadêmica. Argumentam que a investigação da própria prática passou a fazer parte da formação inicial e do desenvolvimento profissional docente. Isso teve impacto também na pesquisa do professor universitário, pois perceberam que havia aumentado o número de docentes do ensino superior que tomavam suas práticas profissionais como objeto de estudo.

Acerca da natureza da aprendizagem docente, naquele mesmo ano as autoras publicaram um artigo importante: "Relationships of knowledge and practice: teacher learning in communities" (Cochran-Smith; Lytle, 1999a). Nesse artigo, questionam a crença de que os professores que sabem mais ensinam melhor. Entretanto indicam diferentes visões sobre os significados de "saber mais" e "ensinar melhor":

Em outras palavras, há concepções radicalmente diferentes de aprendizado de professores, incluindo imagens variadas de conhecimento; de prática profis- 
sional; de relações necessárias e/ou potenciais que existem entre ambos; dos contextos sociais, intelectuais e organizacionais que sustentam o aprendizado do professor; e nas maneiras através das quais este aprendizado se conecta com a mudança educacional e com o propósito da escola. (idem, p. 249)3

As autoras, a partir dessa perspectiva, identificam três diferentes concepções de aprendizagem docente, tendo como base os diferentes entendimentos e relações que se estabelecem entre conhecimento e prática profissional.

A primeira concepção estabelece um relacionamento que as autoras denominam de "conhecimento-para-prática", pois parte do pressuposto de que os acadêmicos e especialistas geram os conhecimentos formais e teorias para que os professores os aprendam para utilizar ou aplicar na prática. Essa concepção supõe que o conhecimento formal serve para organizar e aprimorar a prática profissional do professor. Valendo-se desse pressuposto, conhecer mais (conteúdos, estratégias, teorias educacionais etc.) e aplicar esses conhecimentos ajuda o professor a melhorar sua prática docente. Nesse cenário, os espaços de aprendizagem profissional são geralmente cursos, oficinas e workshops conduzidos por especialistas da universidade. Essa concepção, portanto, segue o modelo da racionalidade técnica, pois, conforme Schön, referenciado por Cochran-Smith e Lytle (idem, p. 263), "presume que os profissionais são solucionadores de problemas e que os problemas da prática profissional [...] podem ser resolvidos instrumentalmente através da aplicação de teorias e técnicas embasadas na pesquisa acadêmica".

A segunda concepção pressupõe que os conhecimentos essenciais para o exercício da docência são de natureza prática e, portanto, não podem ser ensinados, mas aprendidos tácita ou reflexivamente na prática, podendo evoluir com a experiência e mediante interlocução com professores experientes ou considerando a reflexão do professor sobre sua própria prática. Essa concepção de aprendizagem docente estabelece um relacionamento entre conhecimento e prática que é caracterizado pelas autoras como "conhecimento-na-prática".

Se na primeira perspectiva os professores eram considerados usuários ou aplicadores do conhecimento acadêmico-científico, na segunda são vistos como os próprios designers e arquitetos da ação educativa. Entretanto esse conhecimento prático que produzem os professores, por estar situado em contextos locais e isolados, pode, com o tempo, tornar-se rotineiro, naturalizado e reprodutivo de relações e práticas, impedindo que o professor e sua docência possam se desenvolver e se transformar continuamente.

Embora as pesquisadoras reconheçam que os professores aprendem e produzem conhecimentos relevantes na prática, mediante reflexão na ação e sobre a ação de ensinar e aprender, elas propõem que os professores também desenvolvam conhecimentos e teorias por meio da investigação da própria prática, constituindo comunidades investigativas locais conectadas com outras comunidades mais amplas ou globais.

3 As citações dessa obra foram traduzidas aqui pelo Grupo de Estudo e Pesquisa sobre Formação de Professores de Matemática (GEPFPM-FE/UNICAMP). 
É valendo-se dessa perspectiva que Cochran-Smith e Lytle apresentam uma terceira concepção de aprendizagem docente que denominaram de "conhecimento-da-prática”. Nessa concepção, o conhecimento relativo ao ensino é visto como um saber que não pode ser cindido em conhecimento formal (ou teórico) e em conhecimento prático. $\mathrm{O}$ conhecimento que os professores precisam para ensinar bem é gerado quando eles consideram suas próprias práticas como objeto de investigação intencional, considerando as teorias produzidas por outros como aportes ou referências que ajudam a problematizar, interpretar e compreender a prática de ensinar. Trata-se, portanto, de um conhecimento da prática, do qual os professores se apropriam quando geram o conhecimento local "da" prática, trabalhando em comunidades de investigação. Assim, com essas comunidades, os professores, de um lado, teorizam e constroem seu trabalho, conectando-o às questões sociais, culturais e políticas mais amplas e, de outro, desenvolvem uma postura que as autoras caracterizam como investigativa.

Essa terceira concepção é ampliada e profundamente discutida pelas autoras, dez anos mais tarde, em um livro intitulado Inquiry as stance: practitioner research in the next generation (Cochran-Smith; Lytle, 2009). ${ }^{4}$ Nesse livro defendem que a postura investigativa descreve as posições tomadas por professores inseridos em comunidades investigativas em relação ao conhecimento e suas relações com a prática. Mais que o professor realizar uma pesquisa esporádica, em determinado período, as autoras propõem que os professores desenvolvam um modo de ser investigativo. Para isso, discorrem sobre quatro aspectos relacionados à ideia de postura investigativa:

1) concepção de conhecimento local em contextos globais;

2) visão ampliada da prática;

3) comunidades investigativas como meio ou mecanismo primário para adotar uma teoria da ação;

4) justiça social.

Ao discorrerem sobre a natureza do conhecimento - primeiro aspecto abordado no livro -, destacam que querem unir, não separar, o conhecimento local e os contextos e conhecimentos globais. Em outras palavras, Cochran-Smith e Lytle (idem) reconhecem que o conhecimento local gerado por professores em comunidades investigativas pode ser resposta a questões amplas que afetam outros professores. Para isso, defendem a intrínseca relação entre conhecimentos acadêmicos e conhecimentos da prática.

Sobre o segundo aspecto abordado, a visão de prática ampliada "abrange a aprendizagem dos estudantes, bem como as investigações contínuas dos estudantes, professores e líderes nos aspectos da construção dos conhecimentos social, cultural, intelectual, relacional e político" (idem, p. 143). As autoras destacam que essa ideia de prática assemelha-se à ideia de práxis, na qual a prática educacional sempre

4 As citações dessa obra aqui foram traduzidas por Maria Amélia A. Nader e Maristela M. Kondo Claus. 
envolve uma síntese de reflexão crítica e de ação. Nesse sentido, "a visão de prática que estamos sugerindo inclui a ideia de que as pedagogias e as estratégias para a mudança transformativa são inventadas, reinventadas e continuamente negociadas" em diferentes comunidades (idem, p. 147). Nesse sentido, os professores, "além de trabalharem com base no diálogo com os estudantes, também o fazem com colegas e líderes escolares, com outros professores da educação básica, com estudantes de graduação e outros membros do corpo docente e assistentes, com o intuito de tratar de assuntos fundamentais para a educação" (idem, ibidem). Valendo-se dessa concepção de prática, as autoras acreditam que "a investigação do professor tende a mudar as supostas dicotomias entre investigação e prática, entre ser professor e ser pesquisador" (idem, ibidem).

Em relação ao terceiro aspecto, Cochran-Smith e Lytle (idem) apontam que, mediante a participação em comunidades investigativas, os professores têm a possibilidade de constituir o que chamam de teoria de ação, que não é apenas sobre indivíduos, mas também sobre coletividades. Nesse sentido, para elas:

[...] os propósitos e funções essenciais das comunidades investigativas são os de fornecer contextos ricos e desafiadores para a aprendizagem do professor ao longo de sua vida profissional, bem como disponibilizar locais produtivos capazes de vincular as comunidades de educadores aos grandes esforços de mudanças, tanto nacionalmente como internacionalmente. (idem, p. 148)

Por fim, como quarto aspecto, destacam que quando professores pesquisadores em exercício participam de comunidades investigativas:

[...] estão trabalhando a favor e contra o sistema - um processo em curso, partindo do interior, problematizando hipóteses fundamentais sobre os propósitos do sistema educacional existente; sendo esse trabalho realizado por meio do levantamento de difíceis questões sobre os recursos educacionais, processos e resultados. (idem, p. 154)

Desse modo, os professores, colaborativamente, realizam investigações, questionando o currículo existente, o modo de ensino, as práticas de avaliação e as políticas educacionais. Além disso, habilitam-se a compreender como as organizações de ensino e as lideranças escolares desafiam ou sustentam as desigualdades profundas inscritas no status quo. Destacam que a finalidade principal do construto de postura investigativa é "aprimorar a aprendizagem do aluno e as suas chances na participação e contribuição para uma sociedade diferente e democrática" (idem, ibidem).

\section{INFLUÊNCIAS DOS ESTUDOS DE COCHRAN-SMITH E LYTLE NA PRÁTICA E NA PESQUISA BRASILEIRAS SOBRE O PROFESSOR E SUA FORMAÇÃO}

No Brasil, desde que foram iniciadas as discussões sobre o conceito de pesquisa do professor, as obras de Cochran-Smith e Susan Lytle (1990, 1993, 1999a, 
1999b, 2009) têm sido referência e objeto de estudo de vários pesquisadores e grupos de pesquisa sobre formação e desenvolvimento profissional docente. Entre outros, destacamos, numa perspectiva mais ampla, os trabalhos de André (2001); Bueno et al. (1993); Lüdke (2001); Mizukami et al. (2003); Santos (2001); Zeichner e Diniz-Pereira (2005). Numa perspectiva mais estrita, relativa à educação matemática e à formação de professores que ensinam matemática, destacamos os estudos de Crecci e Fiorentini (2013); Fiorentini (2010,2013a, 2013b); Fiorentini e Lorenzato (2006); Passos et al. (2006).

Nessas pesquisas brasileiras, sobretudo aquelas relacionadas à educação matemática, têm sido explorados e utilizados conceitos como aprendizagem docente, comunidades investigativas e postura investigativa, com o propósito de analisar e discutir aspectos referentes à profissionalidade docente e ao desenvolvimento profissional de professores que ensinam matemática e que participam de comunidades colaborativas de aprendizagem profissional ou de investigação sobre a própria prática docente.

De maneira mais específica e sob uma perspectiva diacrônica, tem sido pesquisado como professores e participantes de diferentes tipos de comunidades de aprendizagem docente - sobretudo as comunidades colaborativas e investigativas que têm como foco de análise a prática de ensinar e aprender matemática na escola básica - desenvolvem-se profissionalmente e constituem sua profissionalidade docente nesse contexto.

Mais recentemente, Fiorentini e Coelho (2012) e Fiorentini (2013a, 2013b), por meio de meta-análise qualitativa de pesquisas desenvolvidas por professores no interior de comunidades investigativas e de análise narrativa da trajetória de participação e reificação desses professores nesse contexto, têm buscado identificar, descrever e compreender as aprendizagens, o desenvolvimento profissional e a constituição da profissionalidade docente de professores de matemática nessas comunidades. Para apoiar teórico-metodologicamente esse tipo de pesquisa, esses autores têm tentado estabelecer interlocução entre a teoria social da aprendizagem situada em comunidades de prática (Lave, 1996; Lave; Wenger, 1991; Wenger, 1998) e os estudos da aprendizagem docente de Cochran-Smith e Lytle (1999a, 2009) em comunidades investigativas.

A seguir, apresentamos a entrevista completa realizada com a professora Marylin Cochran-Smith. Nessa interlocução, procuramos discutir, primeiramente, a pesquisa do professor e o processo de investigação sobre a própria prática docente e o que o aproxima e o separa do processo de reflexão sobre a prática. Em segundo lugar, procuramos destacar a aprendizagem e o desenvolvimento do professor em comunidades investigativas. Por último, tentamos saber a opinião da pesquisadora sobre a atual política do Governo Obama sobre a educação e, especialmente, sobre a formação de professores nos Estados Unidos. 


\section{ENTREVISTA COM A PROFESSORA MARILYN COCHRAN-SMITH}

Entrevistadores: Qual a importância das comunidades investigativas para a formação do professor, e como a investigação como postura pode ser desenvolvida por professores em comunidades?

Cochran-Smith: Bem, acredito que as comunidades são um dos poucos lugares em que os professores podem realmente desenvolver a investigação como postura, porque eles constroem ideias com outros professores. Comunidades que são investigativas, ao longo do tempo, desenvolvem normas e entendimentos comuns. $\mathrm{E}$ as pessoas envolvidas nessas comunidades empurram umas às outras para não fazer apenas suposições, mas para levantar questões como, por exemplo: "O que você realmente quer dizer com isso?" "Quais suposições você está fazendo sobre as habilidades de seus estudantes?" "Quais as expectativas que você tem sobre os estudantes que são aprendizes de língua inglesa e que não são falantes nativos?” As comunidades em que Susan Lytle e eu trabalhamos e escrevemos são investigativas, e assim as pessoas trabalham com dados de suas comunidades que trazem para as reuniões. Esses dados podem ser amostras de escrita dos estudantes, trabalhos de matemática dos estudantes, também podem ser documentos de uma escola ou relatórios. E o grupo, então, pode se envolver em vários tipos de investigação, que tem como pano de fundo a seguinte questão: Quais são os pressupostos que estão operando aqui?

Entrevistadores: Há diferenças entre ser reflexivo e tomar a investigação como postura? Cochran-Smith: Na verdade, Susan e eu conversamos sobre isso há anos. Acho que as pessoas que desenvolvem a investigação como postura sobre a própria prática estão sendo reflexivos. Mas a investigação é algo maior que a reflexão, e acredito que nem todo mundo que é reflexivo está necessariamente assumindo a investigação como postura. $\mathrm{O}$ significado cotidiano de refletir ou de reflexão significa ser pensativo, pensar sobre as coisas, prestar atenção... A investigação inclui isso. Inclui também uma gama maior de atividades. Inclui, por exemplo, a sistematização sobre o que se está refletindo. Eu posso ter tido um dia ruim como professora, no qual as crianças não estavam aprendendo o que eu tentava ensinar. Posso pensar sobre isso no meu caminho para a casa: "O que deu errado? O que estava acontecendo ali? Eu não acho que eles entenderam a atividade. Talvez não tenha dado explicações suficientes. Foi muito difícil. Eles não sabiam?” Isso é ser reflexivo, penso eu. Você está fazendo perguntas sobre o que aconteceu em sua sala de aula, está tentando ser aberto às possibilidades. Você não está apenas assumindo que, por ter ensinado, então os estudantes devem ter aprendido.

Mas, se estou comprometida com a investigação como postura, poderia questionar a natureza do ensino de uma forma muito mais sistemática. Eu posso dar um exemplo. Um dos meus estudantes investigou pequenos grupos, observando o tipo de trabalho intelectual que eles realmente realizavam nas classes. $\mathrm{Na}$ sala de aula, onde ele foi realizar estágio, o professor usou pequenos grupos, e esse futuro professor, o meu aluno, achou que esses pequenos grupos não eram necessariamente tão bons. Eram aulas de estudos sociais, e eles estavam tentando utilizar documentos históricos primários. E 
assim, a pergunta que o futuro professor queria explorar era sobre o trabalho intelectual que ocorria ou não nos grupos. Ele descobriu um modo de investigar isso de maneira sistemática. Ele gravava as discussões nos pequenos grupos e recolhia os trabalhos, as anotações, os produtos finais, e relatou o processo de trabalho desses grupos. Ele olhou por meio dos grupos, e comparou, de um dia para o outro, esse tipo de coisa. Ele, na verdade, surpreendentemente descobriu que eles realmente estavam realizando um trabalho muito sofisticado intelectualmente, na maior parte do tempo, e que, mesmo quando não estavam diretamente voltados à tarefa intelectual, algumas das conversas paralelas, na verdade, funcionavam para ajudar a alimentar o estudo. Isso é um exemplo de uma investigação mais ampla, e é diferente do que apenas refletir no caminho de casa: "Por que minha lição não foi boa?" Como disse, a reflexão é parte da investigação, e não pode haver uma postura investigativa sem ser reflexivo, mas você pode ser reflexivo sem fazer investigação.

Entrevistadores: Como você vê e analisa a possibilidade de os professores escolares realizarem pesquisas em comunidades acadêmicas?

Cochran-Smith: Nos Estados Unidos há professores que fazem pesquisa da própria prática ou outros tipos de investigação em trabalhos de mestrado e doutorado, e penso que essas pesquisas são muito legítimas para a geração de conhecimento. Como Susan e eu discutimos em um de nossos primeiros artigos (Cochran-Smith; Lytle, 1990), quando professores olham para suas próprias práticas, questionando seus próprios pressupostos e interrogando os arranjos escolares, eles habilitam-se a produzir, aumentar e alterar os conhecimentos que são úteis para sua comunidade local, e também para além dela. Como costumamos dizer: "Esse tipo de trabalho vai alterar, não apenas aumentar a base de conhecimento". Acredito que precisamos dessa perspectiva mais privilegiada da prática. Eu sou uma defensora de os práticos (professores e gestores escolares em exercício) realizarem pesquisas de mestrado e doutorado sobre suas próprias práticas. Eu vou dar dois exemplos. Uma de minhas estudantes de doutorado, Kirsten McEachern, é professora de inglês no ensino secundário. Ela atua há cerca de dez anos em uma escola católica somente para meninos e está coletando dados para sua tese. Ela é uma das poucas mulheres professoras da escola, e seu projeto é sobre a noção de gênero, isto é, as ideias que os estudantes têm de "homem", "mulher", "menino" e "menina" e que são geradas em um ambiente em que todos os alunos são meninos e quase todos os professores são homens. Ela está usando em sua aula de inglês alguns romances selecionados cuidadosamente que trazem várias questões de gênero, e sua pergunta é sobre como ela e seus estudantes constroem imagens e ideias sobre gênero. Eu penso que será uma contribuição muito valiosa para a literatura do campo educacional.

Outro exemplo é de outra doutoranda, Victoria Ekk, que atualmente está terminando sua tese. Ela é diretora em uma escola e tem recolhido dados de sua prática desde que foi instituída a política do No Child Left Behind (NCLB) ${ }^{5}$ aqui nos Estados Unidos, em 2001. Dessa maneira, ela tem dados relacionados aos últimos cinco anos da implemen-

5 Lei federal dos Estados Unidos que visa assegurar que todas as crianças recebam uma educação de alta qualidade no país. Para isso, realiza testes que responsabilizam com 
tação desse programa de testes e tem, também, algumas reflexões escritas. Ela manteve todos os seus e-mails e anotações de todas as reuniões que fez com membros do corpo docente. Ela está particularmente interessada no impacto que a implementação do NCLB teve em um professor de sua escola e em seus estudantes com deficiência.

Acredito que esses dois trabalhos darão uma contribuição muito importante, porque eles trazem perspectivas privilegiadas da prática. Temos toneladas de estudos sobre o NCLB, mas isso não quer dizer que temos estudos que sistematizem de maneira próxima o que essa política significou e o que significa para as famílias de estudantes com deficiência, e assim por diante. Então, o que acho sobre esses trabalhos na academia? Eu acho que nós precisamos deles e isso enriquece o que podemos saber.

Ressalto, ainda, que não é toda pesquisa que deve ser realizada dessa maneira. Eu não acho que seja a única forma de investigar a prática escolar. Devemos ter a pesquisa dos próprios professores (insiders) e ter pesquisadores externos à escola (outsiders).

Entrevistadores: Esse tipo de pesquisa traz mudanças nos resultados da prática? Cochran-Smith: Bem, não sei se muda. Talvez "mudança” não seja a palavra certa. Sem dúvida, o tipo de pesquisa que você faz, em certo sentido, determina o que você vai encontrar. As perguntas que você faz, e como pergunta, têm total relação com o que você vai encontrar. Há muitos tipos de perguntas. Alguém poderia ter feito um estudo sobre qual o impacto que os resultados dos testes do NCLB tiveram nos estudantes com deficiência, entre outras perguntas. Então não é necessariamente quem faz a pesquisa que impacta nos resultados, mas como você faz as perguntas.

Entrevistadores: Como as políticas de formação de professores podem ser baseadas no conceito de "comunidades investigativas"? É possível realizar projetos como esse em larga escala?

Cochran-Smith: Há alguns lugares onde estão fazendo isso em uma escala maior, e eles têm políticas que exigem que todos os professores participem. Agora, aqui está o problema. Não é só porque você exige que os professores se reúnam em torno de algo que podemos chamar de comunidade que eles vão se envolver em investigação. Por isso, em larga escala, é mais prudente chamar de comunidades de aprendizagem profissional do que de comunidades investigativas. Em Cingapura, por exemplo, a maioria dos professores trabalha em comunidades de aprendizagem profissional em suas escolas. No verão passado, fui para Cingapura e realizei um workshop para diretores, e foi para essa "obrigação" que olhamos. Olhamos a investigação que eles estavam fazendo, mas pouco do que estava acontecendo nessas comunidades era realmente benéfico ao ensino. Não é só porque as pessoas se reúnem em espécies de comunidades de aprendizagem que serão investigativas.

No distrito escolar em que uma de minhas alunas atua, em determinado ponto eles foram obrigados a formar comunidades de aprendizagem profissional. E ela já estava

punição ou bonificação distritos escolares, escolas e docentes pelo desempenho de seus estudantes. 
pensando em como transformar a comunidade obrigatória em investigativa. Agora, o que a torna investigativa? Para mim, o que torna uma comunidade investigativa são as perguntas que vêm dos praticantes, dos professores, e que não são impostas a eles. Em comunidades investigativas, há ativos questionamentos dos pressupostos, das hipóteses, investigações de práticas comuns, há uma tentativa de ser sistemático e há uma cuidadosa consideração às múltiplas perspectivas.

Aqui nos Estados Unidos, em alguns lugares, há exigência de comunidades de aprendizagem profissional que são compreendidas como locais onde os professores podem olhar para os dados dos testes e, em seguida, descobrir como melhorar as notas. Em minha opinião, você poderia ter uma comunidade investigativa que considera os resultados dos testes, mas você precisa ter uma perspectiva muito diferente, isto é, crítica e sistemática, de modo que relacionasse os testes a contextos maiores. Assim, de modo geral, quando tudo é imposto de cima para baixo, não funciona da maneira como concebemos as comunidades investigativas.

Sobre o nome das comunidades, elas têm sido chamadas de diversas maneiras: comunidades de aprendizagem profissional, comunidades investigativas, comunidades de aprendizagem docente. Mas seus nomes não nos dizem como elas operam e não são boas ou ruins por si só. Depende do que acontece dentro dessas comunidades e quais são as perguntas que fazem e tentam responder. Mas a forma como essas comunidades são implementadas, por vezes, são estruturas vazias, e todos os tipos de coisas podem acontecer nessas comunidades, algumas delas positivas e outras não.

Entrevistadores: Nos Estados Unidos há dados indicando que quarenta e seis por cento dos professores abandonam a carreira nos primeiros cinco anos de docência (Ingersoll; Smith, 2003) e que treze por centro abandam no primeiro ano (Ingersoll; Merrill; Stuckey, 2014). Nesse contexto, como o compromisso com a justiça social pode tornar-se parte da agenda dos professores?

Cochran-Smith: Temos um contexto em que a evasão de professores é um grande problema, mas isso é só parte de um contexto maior. Temos um contexto em que há um regime de testes e de responsabilização dos professores que realmente controla muito do que se passa nas escolas. Temos um contexto em que o público, em grande medida, não valoriza o trabalho docente, e não é uma profissão de status elevado. Temos um contexto em que existe um número crescente de desigualdades em termos de oportunidade e resultados para os estudantes da classe média branca e outras minorias. Isso tudo faz parte do contexto e sua pergunta deve ser: "Como poderia o compromisso com a justiça social ser parte do ensino em um contexto como esse?”

Bem, não acredito que seja tão fácil. Eu penso que muitas pessoas vão para o ensino porque querem mudar as coisas. Em todos os anos em que fui educadora e professora são mais de trinta anos -, essa é a resposta que eu mais ouvi dos professores quando se pergunta: "Por que você quer ensinar?" E os professores não dizem: "Porque estarei em férias no verão". Talvez até pensem isso. Mas, principalmente, costuma-se dizer: "Quero fazer diferença na vida das crianças". Eu acho que há uma inclinação que chega ao ensino. As pessoas veem isso como uma profissão que tem a missão de transformar a 
vida das pessoas. Mas, por causa de todas as peças do contexto que eu estava apenas tentando precisar, acho que é muito difícil assegurar o compromisso com a justiça social. As comunidades investigativas são um dos poucos espaços no qual acredito que as pessoas podem obter apoio para a realização do compromisso social, porque estão se sustentando em um grupo, e alguns desses grupos de professores tornam-se grupos de ativistas. Muitos não, mas alguns sim. As pessoas podem se unir e obter o apoio de outros no que eles estão tentando fazer. Algumas escolas tornam-se escolas orientadas para a justiça social. Dessa maneira, acredito que precisamos fazer muito mais para alimentar o desejo de transformação que trazem as pessoas para o ensino.

Infelizmente, temos esse movimento crescente de pessoas que entram no ensino com a intenção de não ficar muito tempo ou de não fazer uma grande diferença. Mas, mesmo que se trate o ensino como uma profissão, eu acho que é muito difícil modificar esse cenário de evasão docente.

Em alguns países, como Cingapura, Escócia, Finlândia e Irlanda, por exemplo, os professores são altamente considerados. Em muitos lugares, os professores são altamente considerados. Mas você tem de investir recursos para isso, e você tem de apoiar os professores ao longo de toda a trajetória profissional. Eu acredito que aqui, nos Estados Unidos, estamos indo na direção errada.

Entrevistadores: Qual tem sido o impacto das pesquisas relacionadas ao professor e à sua formação sobre as práticas e as políticas de formação de professores?

Cochran-Smith: Infelizmente, a pesquisa sobre a formação de professores não tem tido um impacto muito grande na política. Temos a expressão cherry picking, que significa que, em vez de olhar para tudo, para todas as provas, evidências e resultados da investigação, olha-se apenas para os resultados que interessam. Apenas os dados que suportam sua opinião ou sua política. Então, isso é algo que muitas vezes acontece com a investigação sobre formação de professores. Por exemplo, aqueles que são a favor da profissionalização vão falar sobre as evidências empíricas que mostram como os professores são formados, como eles são preparados e que tipo de formação tem mais impacto na aprendizagem dos estudantes. Enquanto pessoas que são a favor da desregulamentação e das políticas baseadas nas reformas empresariais citam evidências que mostram que a formação de professores não tem um impacto muito grande na aprendizagem dos estudantes. Então eles pegam uma cereja, pegam apenas as provas que desejam, e depois acabamos nessas batalhas acaloradas sobre o que diz a pesquisa. Em contrapartida, se olharmos para toda a pesquisa e questionarmos qual é o peso das evidências notadas em sua totalidade, geralmente observamos uma imagem bonita, muito misturada. Mas não podemos, com base nisso, dizer conclusivamente que "essa é a maneira como as pessoas devem ser formadas". E parte do problema é que muitas pesquisas têm feito o que eu e outros pesquisadores temos nos referido como a um tipo de mentalidade de "corrida de cavalos", onde competimos para ver quem tem a melhor abordagem. Perguntamos: "Qual cavalo irá ganhar a corrida?" E isso não é muito útil. Mais recentemente, alguns estudos tentaram não entrar na corrida de cavalos. No entanto, acabaram entrando ao questionarem não apenas o caminho de entrada ou as 
estruturas dos programas de formação de professores, mas também as peças ou fatores que têm influenciado as oportunidades dos candidatos a professores e os resultados para os estudantes. Em síntese, o quadro sobre o impacto da pesquisa em políticas públicas é realmente um quadro misto e problemático.

Entrevistadores: Em 2009, você apontou que estava esperançosa com a eleição do democrata Barack Obama e a pesquisa dos praticantes (professores e gestores) das escolas. Com a continuidade das políticas baseadas em testes, como você vê atualmente essa relação da pesquisa do professor com o ensino?

Cochran-Smith: Justamente quando estávamos terminando esse livro (Cochran-Smith; Lytle, 2009), tivemos a eleição, a primeira eleição em 2008. À época, Susan e eu estávamos defendendo fortemente Barack Obama. Comparando com o que tem sido feito, acho que a agenda da educação de Obama e suas políticas educacionais não foram boas. Estou muito desapontada com a política de formação continuada dos professores e até com a intensificação do regime de testes. Há a ideia de que o accontability vai consertar as coisas. Há a ideia de que, ao aumentar a responsabilização, vai melhorar a qualidade do professor e, consequentemente, a aprendizagem dos estudantes. Prestação de contas sem apoio, recursos e infraestrutura não resolve.

No contexto da agenda Race to the Top,${ }^{6}$ do Governo Obama, para os estados receberem o dinheiro destinado à educação, eles tinham de colocar em prática muitos dos programas de testes e criar novos tipos de sistemas de dados. Nessa agenda, há doze estados que têm recebido Race to the Money Top, e um deles é Massachusetts. A fim de receber esse financiamento, os estados tinham de ter em prática muitos dos programas de testes e criar novos tipos de sistemas de dados, para que pudessem vincular o que eles querem fazer e o que estão fazendo em alguns estados.

$\mathrm{O}$ que querem fazer, na verdade, é vincular a pontuação de estudantes em testes com os dados dos professores e, assim, aos programas de formação destes, para que possam dizer quais são os bons e os ruins. Não acho que essa é a abordagem correta. Eu acredito que há uma grande quantidade de evidências de que os tipos de avaliação que fazem não são apropriados para decisões de altas apostas para os indivíduos, e elas provavelmente não são adequadas para avaliar programas de formação de professores. Eles estão medindo algo, estão capturando algo nessa pontuação, mas o efeito "professor" provavelmente nem tanto. Muitas coisas estão envolvidas na formação de professores, temos os programas, as crianças, as escolas e os contextos.

Um milhão de coisas acontecem nas escolas. O contexto é variado e complexo, e depende de muitas coisas. Diante disso, só votei novamente no Obama porque certa-

6 Fundo de investimento em educação do governo federal dos Estados Unidos. Para receber os recursos, os estados devem adotar quatro princípios básicos: 1) desenvolvimento de avaliações e normas; 2) melhoria nos sistemas de dados; 3) suporte para os professores e dirigentes escolares se tornarem mais eficazes; e 4) maiores intervenções nas escolas com menor rendimento nos testes. 
mente prefiro suas políticas em muitos aspectos em relação às da oposição, mas não concordo com suas políticas na área da educação.

Quanto ao impacto que a pesquisa tem sobre o ensino hoje, acho que é preciso reforçar a ideia de que há maneiras melhores e mais corretas de fazer as coisas. Assim, poderemos provar que alguns caminhos são mais adequados do que outros.

Esse contexto político é problemático, e estão sendo sugeridas pesquisas que são muito diferentes da pesquisa do professor. São sugeridas, por exemplo, pesquisas em grande escala, como os ensaios de controle de testes, inquéritos ou experimentos randomizados. Eu penso que essa modalidade de pesquisa não fornece o tipo de conhecimento que realmente precisamos para mudar as coisas.

Acredito que temos de trabalhar sobre a pobreza. Precisamos enfrentar a pobreza. Por exemplo, precisamos ter certeza de que todo mundo terá seguro de saúde. Políticas que estão até mesmo relacionadas à educação, como os programas de primeira infância e pré-natal. E o presidente Obama defende essas políticas. Assim, praticamente concordo com a posição do presidente em relação a esses assuntos. Concordo com muitas dessas outras políticas, mas não com aquelas voltadas diretamente à educação.

Entrevistadores: Ravitch tem divulgado suas críticas em relação às escolas charters. No Brasil, temos pesquisadores, como Freitas (2012), por exemplo, que criticam os projetos defendidos pelos reformadores empresariais e que chegam para nós, incluindo esse modelo de escola. Qual a sua opinião acerca das escolas charters?

Cochran-Smith: As escolas charters são uma das estratégias favoritas para a reforma da educação básica. Elas certamente estão recebendo financiamento, aplausos e status de favoritas da administração Obama e de muitos governos estaduais. Elas ainda compreendem uma pequena porcentagem das escolas públicas, e precisamos manter isso em consideração.

A melhor pesquisa que conheço usa uma amostra nacional e sugere que as escolas charters não são eficazes. Apenas certa porcentagem, acredito que em torno de vinte e sete por cento, das escolas charters foi melhor nos testes que as escolas públicas. Entretanto, trinta e três por cento de escolas charters foram piores que as escolas públicas. $\mathrm{Ou}$ seja, não há provas convincentes de que as escolas charters são a panaceia que vai salvar tudo para todos. Então, essa alternativa não é a resposta aos nossos problemas. Além disso, sabemos que essas escolas tendem a aumentar a estratificação. Tendem a não servir bem os estudantes com necessidades especiais. Tendem a ter um impacto de segregação de minorias. Em síntese, não acho que esse tipo de escola seja a resposta para os problemas da educação atual. Mas certamente é a abordagem favorita do governo.

Entrevistadores: Você tem questões ou comentários finais que considera importantes para os educadores brasileiros, principalmente em relação à pesquisa do professor? Cochran-Smith: Desde o lançamento de nosso primeiro livro sobre a pesquisa do professor (Cochran-Smith; Lytle, 1993) até a publicação do último sobre a investigação como postura (Cochran-Smith; Lytle, 2009), descobrimos e ficamos surpresas com o movimento mundial da investigação e da pesquisa do professor, tendo atingido 
praticamente todo o mundo. Há grupos nas escolas, há parcerias entre universidade e escola, e universidades que apoiam e sustentam esse empreendimento.

Há comunidades ao redor do mundo em que pessoas usam a pesquisa da própria prática como meio para tentar avaliar suas práticas, trabalhar com outras pessoas e abordar diferentes questões complexas. Foi surpreendente, especialmente nos Estados Unidos e em alguns outros lugares, tendo em vista o contexto problemático do qual falávamos. Mas essas comunidades ainda estão lá. Então, como estávamos falando, a pesquisa do professor está viva e bem, embora em uma variedade de maneiras que nem sempre corresponde ao que defendemos.

Outra coisa que aprendi foi a forma como muitas das comunidades investigativas trabalham com questões relacionadas à diversidade, à igualdade de acesso e à equidade. Esses parecem ser os principais tópicos que esses grupos vêm discutindo e investigando. Então acredito que esse quadro aponta para o fato de que a pesquisa praticamente é uma abordagem muito útil para tentar lidar com essas questões que são as mais importantes do nosso tempo no que se refere à educação. $\mathrm{O}$ que acabamos de dizer, no final do livro, em 2009, foi que há múltiplas maneiras de construir esses espaços, e temos de ampliar a agenda por meio da ligação com outras comunidades, pelo aprofundamento do trabalho nas comunidades locais, pela colaboração com outros envolvidos em grandes movimentos sociais. Embora não sejam sobre a pesquisa do professor, compartilham algumas de suas premissas. Em certo sentido, é um momento difícil para defender a pesquisa do professor, mas há muitas pessoas envolvidas nesse empreendimento, de modo que acredito ser essa uma ideia muito importante e que não podemos perdê-la de vista.

\section{REFERÊNCIAS DE ESTUDOS DE COCHRAN-SMITH E LYTLE}

Cochran-Smith, M. Composing a research life. Action in Teacher Education, London: Routledge, v. 34, n. 2, p. 99-110, 2012.

.; Lytle, S. Research on teaching and teacher research: the issues that divide. Educational Researcher, London: Sage, v. 19, n. 2, p. 2-11, 1990.

.; In Inside/outside: teacher research and knowledge. New York: Teachers College Press, 1993.

.; Relationships of knowledge and practice: teacher learning in communities. Review of Research in Education, London: Sage, n. 24, p. 249-305, 1999a.

London: Sage, v. 28, n. 7, p. 15-25, 1999b.

;_ Inquiry as stance: practitioner research for the next generation. New York: Teachers College Press, 2009.

Changing perspectives on practioner research. Learning Landscapes,

Quebec: Learn, v. 4, n. 2, p. 17-23, 2011. 


\section{REFERÊNCIAS DE ESTUDOS BRASILEIROS SOB INFLUÊNCIA DE COCHRAN-SMITH E LYTLE}

AndrÉ, M. Pesquisa, formação e prática docente. In:___. (Org.). O papel da pesquisa na formação e na prática dos professores. Campinas: Papirus, 2001. p. 55-69.

Bueno, B. O.; Sousa, C. P.; Catani, D. B.; Souza, M. C. C. C. Docência, memória e gênero: estudos alternativos sobre a formação de professores. Psicologia USP, São Paulo: USP, v. 4, n. 1-2, p. 299-318, jan. 1993. Disponível em: <http://www.revistas.usp.br/ psicousp/article/view/34482 >. Acesso em: 19 maio 2015.

Crecci, V. M.; Fiorentini, D. Desenvolvimento profissional de professores em comunidades com postura investigativa. Acta Scientiae, Canoas: ULBRA, v. 15, n. 1, p. 9-23, jan./abr. 2013. Disponível em: <www.periodicos.ulbra.br/index.php/acta/ article/download/346/362 >. Acesso em: 29 dez. 2015.

Fiorentini, D. Desenvolvimento profissional e comunidades investigativas. In: Dalben, Â.; Dinız, J.; Leal, L.; Santos, L. (Orgs.). Convergências e tensões no campo da formação e do trabalho docente: educação ambiental - educação em ciências - educação em espaços não escolares - educação matemática. Belo Horizonte: Ática, 2010. p. 570-590.

. Aprendizagem profissional e participação em comunidades investigativas. In: Encontro Nacional de Educação Matemática, 11., 2013, Curitiba. Anais... Curitiba: Sociedade Brasileira de Educação Matemática, jul.2013a.p. 1-15. Disponível em: <http://sbem.bruc.com.br/XIENEM/pdf/2988_2195_ID.pdf>.Acesso em: $12 \mathrm{dez}$. 2013.

. Learning and professional development of mathematics teacher in research communities. Sisyphus - Journal of Education, Lisboa: Instituto de Educação da Universidade de Lisboa, v. 1, n. 3, p. 152-181, 2013 b.

.; Coelno, M.A. V. Aprendizagem profissional de professores em comunidades investigativas. Leitura: Teoria Ė Prática, Campinas: ALB, v. 30, n. 58, p. 1.053-1.062, 2012.

.; Lorenzato, S. Investigação em educação matemática: percursos teóricos e metodológicos. Campinas: Autores Associados, 2006.

Freitas, L. C. Os reformadores empresariais da educação: da desmoralização do magistério à destruição do sistema público de educação. Educação E Sociedade, Campinas: CEDES, v. 33, n. 119, p. 379-404, 2012.

Ingersoll, R.; Smith, T. The wrong solution to the teacher shortage. Educational Leadership, Philadelphia: United States GSE Publications. v. 60, n. 8, p. 30-33, 2003.

.; Merrill, L.; Stuckey, D. Seven trends: the transformation of the teaching force. Philadelphia: University of Pennsylvania; Consortium for Policy Research in Education (CPRE), 2014. Disponível em: <http://cpre.org/sites/default/files/working papers/1506_7trendsapril2014.pdf $>$. Acesso em: 3 maio 2014.

Lave, J. The practice of learning. In: Chaiklin, S.; Lave, J. (Eds.). Understanding practice: perspectives on activity and context. New York: Cambridge University Press, 1996. p. 3-32. 
.; WENGER, E. Situated learning: legitimate peripheral participation. Cambridge: Cambridge University Press, 1991.

LÜDKE, M. A complexa relação entre o professor e a pesquisa. In: André, M. (Org.). O papel da pesquisa na formação e na prática dos professores. Campinas: Papirus, 2001.p. 27-54. Mizukami, M. G.; Reali, A. M. R. R.; Reyes, C. R.; Martucci, E. M.; Lima, E. F.; TANCREDI, R. M. S. P.; Mello, R. R. Escola e aprendizagem da docência: processos de investigação e formação. São Carlos: EDUFSCAR; INEP/COMPED, 2003.

Passos, C. L. B.; Nacarato, A. M.; Fiorentini, D.; Miskulin, R. G.; Grando, R. C.; Gama, R. P. et al. Desenvolvimento profissional do professor que ensina matemática: uma meta-análise de estudos brasileiros. Quadrante: Revista Teórica e de Investigação, Lisboa: Associação de Professores de Matemática, v. 15, n. 1-2, p. 193-219, 2006.

SAntos, L. Dilemas e perspectivas na relação entre ensino e pesquisa. In: ANDRÉ, M. (Org.). O papel da pesquisa na formação e na prática dos professores. Campinas: Papirus, 2001.p. 11-26.

Wenger, E. Communities of practice: learning, meaning, and identity. Cambridge: Cambridge University Press, 1998.

Zeichner, K. M.; Diniz-Pereira, J. E. Pesquisa dos educadores e formação docente voltada para a transformação social. Cadernos de Pesquisa, São Paulo: Fundação Carlos Chagas; Campinas: Autores Associados, v. 35, n. 125, p. 63-80, maio/ago. 2005.

\section{SOBRE OS AUTORES}

Dario Fiorentini é doutor em educação pela Universidade Estadual de Campinas (UNICAMP). É professor na mesma instituição.

E-mail: dariof@unicamp.br

VAnessa Crecci é doutoranda em educação pela Universidade Estadual de Campinas (UNICAMP).

E-mail: vancrecci@gmail.com 